\title{
More Harm than Public Health in Drug Policy? A Comment
}

\author{
Joanne Csete
}

\begin{abstract}
Well-conceived drug-control policies could contribute importantly to economic and social development and public health. Unfortunately, the reality of drug policies in most countries is rather that they undermine public health by failing to protect people who use drugs from infectious disease and the risk of drug overdose. Drug laws and policies that mandate incarceration for minor, non-violent drug offences have profound health costs as the risk of infectious disease in prison is high, and too few prisons offer appropriate health services for people who use drugs. Overly zealous drug-control policies, moreover, have led to enormous human suffering, as many countries have restricted the use of opioids for the relief of pain associated with cancer and other conditions. Protection of the health of communities involved with the production of drug crops such as coca leaf and opium poppy has rarely figured in 'alternative development' programmes for these populations. A few countries have shown that intentionally health-focused drug-control policies can lessen some of these harms.
\end{abstract}

\section{$1 \quad$ Introduction}

Health is rightly understood as both a precondition of development and a crucial outcome of development processes and policies. Policies on psychotropic drugs have the potential to influence public and individual health positively, one route by which they might contribute to sustainable development. However, even as it has become almost obligatory in international drug policy circles for governments to espouse 'public health approaches' to drug policy issues, it is clear that drug policymaking is taking a toll on the health of people and communities touched by drug consumption, drug crop cultivation and drug law enforcement. In most countries, drug policies consistent with good public health practices have been much harder to find than the corresponding rhetoric. This chapter considers ways in which drug policies undermine public

(C) JOANNE CSETE, 2020 | DOI:10.1163/9789004440494_015

This is an open access chapter distributed under the terms of the CC-BY-NC 4.o licenseanne Csete - 9789004440494 
health but, by extension, have the potential to contribute greatly to the health of the public and thus to sustainable development.

\section{Infectious Disease}

The importance of drug policies and programmes, both for national responses to infectious diseases and for the health of individuals, is well documented. As noted by the Joint UN Programme on HIV/AIDS (UNAIDS), '[a]mid the widespread stigma and discrimination, violence and poor health faced by people who use drugs, [they] are beset by persistently high rates of HIV' (UNAIDs, 2019, 2). The incidence (rate of new infections) of HIV declined by about 25 per cent in the global population from 2010 to 2017. Yet among people who use drugs, it increased in many countries, particularly outside of the European Union (EU) (UNAIDS, 2019, 2). Hepatitis and tuberculosis also disproportionately affect people who use drugs, partly because in many countries they are likely to find themselves in prison or jail at some point, settings that can be incubators of тв, hepatitis and HIV.

Drug-related infectious diseases are preventable by well-understood, effective and cost-effective measures. With regard to HIV, hepatitis C, and tuberculosis, governments' failure to invest in drug-related harm reduction measures is a global health tragedy. Vast evidence supports the fact that HIV, for example, can be well contained among people who inject drugs by ensuring their ready access to clean injection equipment and, for people who use opioids, by making opioid maintenance therapies and other well-tested treatments easy to take up and sustain, including in prison (UNAIDS, 2019).

In most of the EU and Switzerland, harm reduction services with respect to infectious disease are extensive and well established as part of drug policy. HIV incidence among people who inject drugs is rare in these countries (European Monitoring Centre for Drugs and Drug Addiction, 2019b). Equally importantly, countries in which drug use and the possession of drugs for personal use are decriminalised or at least not penalised - that is, people are not incarcerated for minor infractions - are able to steer people to the health and social services they may need, rather than undermining their health by incarceration.

Some lower-income, lower-middle-income, and middle-income countries have also made strides in drug-related harm reduction with respect to infectious disease outcomes. For example, Moldova has sustained a widely praised syringe programme in its prisons for many years (HRI, 2018). Numerous countries-including Malaysia, Afghanistan, India, Vietnam, Kyrgyzstan and Mauritius - have established methadone maintenance therapy in at least 
one prison setting (HRI, 2018). In the Middle East and North Africa, Morocco and Iran have pioneered methadone therapy, Iran in prisons as well as in the community, showing the feasibility of this intervention in middle-income countries (Himmich and Madani, 2016).

Sub-Saharan African countries have, in many cases, struggled to sustain harm reduction activities, but there are some successes. Tanzania led the way in the region with a methadone programme launched in 2011. Integrated methadone and HIV treatment services have been piloted there more recently (Cooke et al., 2019). Kenya and South Africa have followed, with methadone programmes as well as sterile syringe programmes (HRI, 2018). Controversies remain, especially around needle exchange. For example, the city of Durban, South Africa (now part of the eThekwini Metropolitan Municipality) discontinued its needle exchange in 2018, alleging that the service was ineffective in curbing the unsafe disposal of syringes (Scheibe et al., 2020). Although many of these programmes have benefited from donor support, there is substantial evidence that harm reduction interventions such as these are cost-effective as investments for governments in countries of all income levels, mostly because of savings from averted HIV and hepatitis C transmission (Wilson et al., 2015).

Investment in harm reduction services is, in many countries including the United States (US), impeded by the scientifically unsound idea that the only way to deal with health problems associated with drug use is to insist on abstinence from all drug use (HRI, 2018; Smith, 2019). Harm reduction is thus alleged to facilitate or encourage drug use, even though there is no evidence that providing clean syringes or a safe space to inject drugs leads people to initiate drug use or to sustain drug use longer than they otherwise would.

In addition to infectious disease, morbidity and mortality related to drug overdoses are beginning to be seen on a previously unimaginable scale, due partly to the dramatic expansion of markets for fentanyl and other lethal synthetic opioids. In the US, for example, overdose deaths linked to opioids increased six-fold from 1999 to 2017 (Scholl et al., 2019). Overdoses were an important contributor to a decline in life expectancy among some age groups in the white population, a phenomenon rarely seen in US history (Woolf and Schoomaker, 2019). About 6o per cent of overdose deaths in the US in 2017 were linked to synthetic opioids, mostly fentanyl, a 45 per cent increase over the 2016 level (Scholl et al., 2019). The proportion of overdose deaths linked to fentanyl in Canada rose from an estimated 5o per cent in 2016 to 73 per cent in 2018 and to 
79 per cent in the first quarter of 2019 (Government of Canada, 2019). Fentanyl and its analogues such as carfentanil are among the most lethal examples of new psychotropic substances (NPS s) - relatively easy to manufacture, usually potent in tiny doses, and requiring new laws and law enforcement approaches globally.

As with infectious diseases, death and disability linked to drug overdoses are eminently preventable. Overdose mortality in the EU in 2017 was estimated at 22.6 deaths per million of population, about one tenth the rate of 217 per million in the US that year (European Monitoring Centre for Drugs and Drug Addiction, 2019a). This difference undoubtedly reflects the much greater policy embrace of overdose prevention measures in the EU compared to the US, including the testing of street drugs for toxins, ensuring availability of naloxone for recently released prisoners and others at risk, as well as emergency medical personnel, supervised consumption sites, and the prescription of medical-grade heroin for selected patients (discussed below). The overdose mortality crisis in the US is directly related to decades of unscientific demonisation of these and other overdose-related harm reduction measures (Chen et al., 2019).

In Canada, where policy-level and programmatic development of harm reduction services is more advanced than in the US, there has been a recognition in some circles of the need for services that not only mitigate the effects of an overdose (such as naloxone distribution and supervised consumption sites), but more directly address the toxins in street drugs that are causing overdose (Fischer et al., 2019). Some Canadian policymakers and service providers have called for an expansion of the harm reduction pillar of their drug policy to include more of these 'safe supply' measures (Vancouver City Council, 2019). Safe supply means ensuring access to safer versions of the drugs people regularly use, including heroin, rather than leaving people to rely on street drugs of unknown origin.

Supervised provision of medical-grade heroin to allow people to avoid the harms of street drugs - a prime example of safe supply-has been part of drug policy for some time in Switzerland, Germany, the Netherlands, the United Kingdom, Denmark and more recently Canada (Strang et al., 2015). These programmes have generally been conceived as intentionally smallscale for the relatively small proportion of people who use opioids for whom methadone and other traditional therapies have not been optimally effective. But widespread adulteration of street drugs with lethal substances argues for the expansion of such programmes. The argument cannot go far, however, in places where harm reduction is seen only as facilitating drug use. The same may be said for drug testing, another safe-supply programme that is underused 
for political, not scientific, reasons. Drug testing means using fentanyl strips or more sophisticated tools such as mass spectrometry to detect adulterants in street drugs before they are ingested. Again, numerous NGO s conduct drug testing, especially at night spots and festivals, in the EU (European Monitoring Centre for Drugs and Drug Addiction, 2019b), but this activity remains relatively rare in the US and in lower-income countries. It is unsurprising that prescription heroin programmes are found only in higher-income countries since these programmes have relatively heavy requirements in terms of human resources and security measures. However, some testing of street drugs is possible with relatively low-cost equipment and does not require highly trained medical personnel.

\section{Access to Controlled Medicines}

Beyond treatment for drug use disorders (DUD s), opioids and other psychotropic medicines have a wide range of clinical uses, including for persons living with pain and those with terminal conditions. The World Health Organization (wHO) encourages national policymakers to find a balance between ensuring that controlled medicines are available to those who need them and ensuring that these medicines are not diverted to non-medical use (wHO, 2011). It is clear that overzealous drug-control policies in many countries have resulted in unbalance, to the point where doctors are afraid to prescribe medicines that are associated with criminal sanctions for non-medical use. Furthermore, the drug-control hoops through which they must jump are perceived as too onerous to be worth the trouble (Burke-Shyne et al., 2017).

As noted by the Lancet Commission on Palliative Care, there is thus an 'access abyss'. For example, a miniscule 0.1 ton of the approximately 300 tons of morphine used in the world is used in low-income countries (Knaul et al., 2017). Millions of terminal patients die in needless pain, and millions suffer from chronic pain over long periods in low- and middle-income countries, as essential controlled medicines for palliative care and pain relief stay largely in high-income countries. As the Lancet Commission asserts:

A prevalent but unwarranted fear of non-medical use and addiction to opioids [...], both among health-care providers and regulators and among patients and their families, has led to insufficient medical use. Unbalanced laws and excessive regulation perpetuate a negative feedback loop of poor access that mainly affects poor people [...] Efforts to prevent nonmedical use of internationally controlled substances, such as morphine 
and other opioid analgesics, have overshadowed and crippled access to opioids for palliative care [...] [and other] legitimate health needs.

KNAUL et al., 2017, 1398

Drug-control authorities and health ministries urgently need to work with legislators and other policymakers to find a way to ensure that drug policies do not add to this unnecessary and massive human suffering.

The Lancet Commission noted progress in a few countries-including Mexico, Jamaica and Vietnam-but concluded that the mentality associated with the over-regulation of controlled medicines by drug authorities can take a long time to overcome, even when better policies are in place. This point is well illustrated in India. One estimate suggests that as many as 10 million people may have needed palliative care in India in 2015, but there was virtually none to be had (Jacob and Mathew, 2017). Although morphine and penthadine were prescribed for palliative care in India before 1985 , the Narcotic Drugs and Psychotropic Substances (NDPS) Act of that year introduced burdensome requirements for physicians to obtain permission to prescribe them, instilling fear of arrest if the requirements were not met. As a result, the use of these medicines fell dramatically (Jacob and Mathew, 2017). Following concerted advocacy by palliative care advocates, an amendment to NDPS in 2014 lightened these requirements and eased fears among physicians about using these medicines. However, both a long period of little or no training of physicians in palliative care and a culture among patients of fearing opioids and hiding pain have remained obstacles to better use. A more effective official strategy and longer experience with palliative care in the southern state of Kerala, which include extensive training of health professionals, may signal a way forward for the country (Jacob and Mathew, 2017; Laurance, 2017).

\section{Health Problems Associated with Law Enforcement and} Incarceration

As already noted, when drug use and minor possession are not punished by imprisonment or other harsh penalties, access to health and social services is obviously greatly facilitated. Avoiding the health consequences associated with incarceration and involvement with criminal law systems is desirable. Because of harsh drug laws, including significant custodial sentences for small-scale possession, drug use disorders are over-represented in prison populations in many countries (PRI, 2018). With the exception of a number of EU countries, 
Canada, and Australia, relatively few countries offer treatment of drug use disorders in prisons (HRI, 2018) - again despite evidence that methadone programmes, for example, are very effective and manageable in this setting.

It is well documented that where prisons do not offer treatment for those with opioid use disorder, overdose risk for these persons is high in the first days after release (Binswanger, 2019). Where treatment is offered in prison, links to treatment providers in the community can be made to ensure that people who are released from prison have a smoother transition to care once outside prison walls. Ensuring access to naloxone for recently released persons and their family and friends can also save lives, but it is a priority in too few countries (HRI, 2018). Treatment for drug use disorders in prisons and links to care upon release are cost-effective and feasible best practices, but they are impeded by the low priority of prison health, moral judgments against prisoners and people who use drugs, and unscientific prejudice against harm reduction.

In some countries, people charged with drug offences are particularly susceptible to being held while awaiting trial, often because they are unable to pay bail—or bribes — to secure pretrial release. Pretrial detention settings are probably even less likely than prisons to offer any kind of treatment for drug use disorders. The Global Fund to Fight AIDS, тв and Malaria (2017) advises its grantees that reducing reliance on pretrial detention can be an important means of reducing prison overcrowding, which is a major contributor to тв in prisons and undoubtedly an overall impediment to improving health services for people in the custody of the state. Reduction of prison overcrowding is appropriately seen as part of health-based drug policy. For people who use drugs, overcrowding in non-prison settings is also a тв risk factor (Deiss et al., 2009).

True alternatives to incarceration for drug-related offences can also be an important part of health-oriented drug policy. Unfortunately, some countries that claim they are trying to see people who use drugs as 'patients, not criminals' do not seem to exemplify good health practices (Csete and Wolfe, 2017). Too many countries, notably in East and Southeast Asia, impose 'treatment detention' on people, in institutions that resemble forced labour camps and rarely have any scientifically sound treatment services (Lunze et al., 2018). Detention and coerced labour must not be imposed in the name of treatment. Cruel, inhuman and degrading practices too often figure prominently in what is called 'treatment' for DUDs, and in detention centres these practices are hard to monitor and reform.

Police practices can also contribute to positive or negative health outcomes among people who use drugs. Aggressive and repressive policing can cause people who use drugs to engage in more dangerous practices—such as 
injecting rather than smoking - and to seek refuge in more remote and dangerous places, where harm reduction services are hard to find (Jürgens et al., 2010). Too many countries still reward and promote drug police based on the number of arrests they make, which tends to encourage arrests of small-scale users who are often the lowest-hanging fruit-exactly the population that should be steered out of the criminal law system and towards health services. Arrest quotas may also push police to focus their activities near needle exchange sites or other places where people who use drugs may congregate, a practice that may discourage use of these vital services.

It is encouraging that police forces in some cities are seeking to do better. The Open Society Foundations have documented a number of cases, including in low-income countries, where, after training and with the support of senior police officials, police have modified their practices to minimise interference with or even to encourage the use of health and harm reduction services (OSF, 2018). Police in some jurisdictions, even in places with harsh drug laws such as the US, have agreed to steer people engaged in minor drug infractions to health and social service-providers rather than into the criminal legal system (OSF, 2018).

\section{Health among Drug Crop Growers}

Challenges associated with efforts at alternative development for households and communities involved with the production of coca, opium poppy, cannabis and other drug crops are described elsewhere in this volume. It is worth underscoring that alternative development programmes have generally neglected both the lingering health consequences of crop eradication efforts and the importance of ensuring access to health services as part of development initiatives. The long-term health impact of decades of mass spraying of coca fields in the Andes with glyphosate, for example, may not be known for years. But the work of Camacho and Mejía (2017), for example, suggests that the short-term consequences of this action may include an elevated risk of miscarriage, respiratory illness, and dermatological problems. In 2015, the International Agency for Research on Cancer (IARC), a group affiliated with the wHO, declared glyphosate a probable carcinogen based on a review of about 1,000 studies by independent experts (Guyton et al., 2015). Monsanto (acquired by Bayer in 2018), the principal manufacturer of glyphosate under the brand name RoundUp ${ }^{\circledR}$, faces legal actions in several countries from claimants alleging cancer incidence linked to the product (Croft, 2019). Aside from the effects of eradication, the work of processing coca leaves into coca paste and cocaine 
also poses health hazards that are often not addressed due to the illicit nature of the work (Grisaffi, 2014).

As Buxton (2015) notes in her critique of alternative development schemes, health is at the centre of every internationally agreed concept of sustainable human development, but it is sorely lacking as a central element of many alternative development schemes for drug crop producers. Ensuring access to health services, which is often precarious for communities depending on illicit drug markets for survival, should be a priority in alternative development. The Doi Tung development effort in opium poppy-growing regions of Thailand beginning in the 1980s and the innovative cato scheme in Bolivia, both regarded as successful alternative development efforts, featured significant investments in health, education and transportation infrastructure as central activities (Williamson, 2005; Ledebur and Youngers, 2013).

\section{7}

Conclusions

Evidence-based, health-focused drug policies could be an avenue leading to the improved health of the public and thus sustainable development. They could help the public worldwide to understand and confront the social determinants and stigma of drug dependence and the futility of abstinence-only approaches. They plainly could play a direct role in the reduction of infectious diseases and lethal overdoses. They could help to save millions of people living with pain from their suffering. They could be an example and a vehicle for criminal justice reform of the kind that would underscore the importance of alternatives to incarceration for non-violent offences, and could greatly improve the health of communities affected by draconian drug laws and law enforcement. They could improve the quality of life of people whose livelihoods depend on the production of drugs and drug crops.

But the history of drug control, by contrast, is littered with policies energised by pious moral judgement, implemented by gross misapplication of criminal law, and exemplifying a rejection of science that is at times nearly inexplicable. The explosive spread of HIV linked to drug injection in the 1980s and 199os led some countries, especially in Europe, to find ways to allow some consideration of good public health practices to temper repressive drug policies, at least to some degree. It remains to be seen whether the overdose mortality crisis in North America, which is unfortunately likely to spread to other regions with the proliferation of fentanyl markets, will create new corners of policy space in which scientifically sound drug control may emerge. 


\section{References}

Binswanger, I.A. (2019) 'Opioid Use Disorder and Incarceration-Hope for Ensuring the Continuity of Treatment', New England Journal of Medicine, 380, pp. 1193-1195, DoI: 10.1056/NEJMp19ooo69.

Burke-Shyne, N., Csete J., Wilson D., Fox E., Wolfe D. and J.J.K. Rasanathan (2017) 'How Drug Control Policy and Practice Undermine Access to Controlled Medicines', Health and Human Rights Journal, 19(1), pp. 237-252.

Buxton, J. (2015) Drugs and Development: The Great Disconnect, Policy Report 2, (Swansea, UK: Global Drug Policy Observatory), https://www.swansea.ac.uk/media/Drugsand-Development-The-Great-Disconnect.pdf (accessed on 25 November 2019).

Camacho, A. and D. Mejía (2017) 'The Health Consequences of Aerial Spraying Illicit Crops: The Case of Colombia', Journal of Health Economics, 54, pp. 147-16o, DOI: 10.1016/j.jhealeco.2017.04.005.

Chen, Q., Larochelle, M.R., Weaver, D.T., Lietz, A.P., Mueller, P.P., Mercaldo, S., Wakeman S.E., Freedberg, K.A., Raphel, T.J., Knudsen, A.B., Pandharipande, P.V. and J. Chhatwal (2019) 'Prevention of Prescription Opioid Misuse and Projected Overdose Deaths in the United States', JAMA Network Open, 2(2), e187621. DoI: 10.10o1/jamanetworkopen.2018.7621.

Cooke, A., Saleem H., Hassan S., Mushi, D., Mbwambo, J. and B. Lambdin (2019) 'Patient and Provider Perspectives on Implementation Barriers and Facilitators of an Integrated Opioid Treatment and HIV Care Intervention', Addiction Science \& Clinical Practice 14(1), 3, DOI: 10.1186/s13722-019-0133-9.

Croft, A. (2019) 'As RoundUp Lawsuits Pile Up by the Thousands, Bayer Remains Defiant', Fortune, 30 October, https://fortune.com/2019/10/30/roundup-lawsuits-bayerdefiant/ (accessed on 27 April 2020).

Csete, J. and D. Wolfe (2017) 'Seeing through the Public Health Smoke-screen in Drug Policy', International Journal of Drug Policy 43, pp. 91-95, DoI: 10.1016/j.drugpo.2017.02.016.

Deiss, R.G., Rodwell T.C. and R.S. Garfein (2009) 'Tuberculosis and Drug Use: Review and Update', Clinical Infectious Disease 48(1), pp. 72-82, DoI: 10.1086/594126.

European Monitoring Centre for Drugs and Drug Addiction (2019a) Drug-Related Deaths and Mortality in Europe: Update from the EMCDDA Expert Network (Luxembourg: Publications Office of the European Union). http://www.emcdda.europa.eu/ system/files/publications/11485/20193286_TDo319444ENN_PDF.pdf (accessed on 19 March 202O).

European Monitoring Centre for Drugs and Drug Addiction (2019b) European Drug Report 2019: Trends and Developments (Luxembourg: Publications Office of the European Union), http://www.emcdda.europa.eu/system/files/publications/11364/ 20191724_TDAT19oo1ENN_PDF.pdf (accessed on 25 November 2019). 
Fischer, B., Pang M. and M. Tyndall (2019) 'The Opioid Death Crisis in Canada: Crucial Lessons for Public Health', The Lancet Public Health, 4(2), pp. e81-e82, DoI: 10.1016/ S2468-2667(18)30232-9.

(The) Global Fund to Fight AIDs, тв and Malaria (2017) Technical Brief: Tuberculosis, Gender and Human Rights (Geneva: The Global Fund), https://www.theglobalfund. org/media/6349/core_tbhumanrightsgenderequality_technicalbrief_en.pd$\mathrm{f} ? \mathrm{u}=637066545910000000$ (accessed on 24 November 2019).

Government of Canada (2019) National report: apparent opioid-related deaths in Canada (Ottawa: Public Health Agency of Canada) https://health-infobase.canada.ca/datal$\mathrm{ab} /$ national-surveillance-opioid-mortality.html (accessed on 25 November 2019).

Grisaffi, T. (2014) 'Can You Get Rich from the Bolivian Coca Trade? Cocaine Paste Production in the Chapare', Andean Information Network (10 March), https://ainbolivia.org/2014/o3/can-you-get-rich-from-the-bolivian-cocaine-trade-cocainepaste-production-in-the-chapare/ (accessed on 27 April 2020).

Guyton, K.Z., Loomis D., Grosse Y., El Ghissassi F., Benbrahim-Tallaa L., Guha N., Scoccianti C., Mattock H. and K. Straif (2015) 'Carcinogenicity of Tetrachlorvinphos, Parathion, Malathion, Diazinon, and Glyphosate', The Lancet Oncology 16(5), pp. 490-491, DOI: 10.1016/S1470-2045(15)70134-8.

Himmich, H. and N. Madani (2016) 'The State of Harm Reduction in the Middle East and North Africa: A focus on Iran and Morocco', International Journal of Drug Policy, 31, pp. 184-189, DoI: 10.1016/j.drugpo.2016.02.013.

HRI (Harm Reduction International) (2018) The Global State of Harm Reduction 2018 (London: HRI), https://www.hri.global/global-state-harm-reduction-2018 (accessed on 26 November 2019).

Jacob, A. and A. Mathew (2017) 'End-of-Life Care and Opioid Use in India: Challenges and Opportunities', Journal of Global Oncology, 3(6), pp. 683-686, Dor: 10.1200/ JGO.2016.00849o.

Jürgens, R., J. Csete, J.J. Amon, S. Baral and C. Beyrer (2010) 'People Who Use Drugs, HIV, and Human Rights', The Lancet, 376(9739), pp. 475-485, DoI: 10.1016/So14O6736(10)6o83o-6.

Knaul, F.M., Farmer P.E., Krakauer E.L., De Lima L., Bhadelia A., X.J. Kwete, ArreolaOrnelas, H., Gómez-Dantés, O., Rodriguez, N.M., O Alleyne, G.A.,Connor, S.R., Hunter, D.J.,Lohman, D., Radbruch, L., del Rocío Sáenz Madrigal, M., Atun, R., Foley, K.M., Frenk, J., Jamison, D.T. and M.R. Rajagopal (2017) 'Alleviating the Access Abyss in Palliative Care and Pain Relief - an Imperative of Universal Health Coverage: The Lancet Commission Report', The Lancet, 391(10128), pp. 1391-1454, DoI: $10.1016 /$ So140-6736(17)32513-8.

Laurance, J. (2017) 'India's Movement to Help People Die Better', The Atlantic, 28 February. https://www.theatlantic.com/health/archive/2017/02/india-palliative-care/ 517995/ (accessed on 18 March 2020). 
Ledebur, K. and C.A. Youngers (2013) 'From Conflict to Collaboration: An Innovative Approach to Reducing Coca Cultivation in Bolivia', Stability: International Journal of Security and Development, 2(1), pp 1-11, DOI: 10.5334/sta.aw.

Lunze, K., Lermet O., Andreeva V. and F. Hariga (2018) ‘Compulsory treatment of Drug Use in Southeast Asian Countries', International Journal of Drug Policy, 59, pp. 10-15, DoI: 10.1016/j.drugpo.2018.o6.oog.

osf (Open Society Foundations) (2018) Police and harm reduction: How law enforcement can advance public safety, public health and public confidence (New York: OsF), https://www.opensocietyfoundations.org/publications/police-harm-reduction (accessed on 26 November 2019).

PRI (Penal Reform International) (2018) Global Prison Trends 2018 (London: PRI), https://www.penalreform.org/resource/global-prison-trends-2018/ (accessed on 25 November 2019).

Scheibe, A., S. Shelly, T. Gerardy, Z. von Homeyer, A. Schneider, K. Padayachee, S. Balaguru Naidoo, K. Mtshweni, A. Matau, H. Hausler and M. Marks (2020) 'Six-month Retention and Changes in Quality of Life and Substance Use from a Low-Threshold Methadone Maintenance Therapy Programme in Durban, South Africa', Addiction Science \& Clinical Practice, 15(13), DOI: 10.1186/s13722-020-00186-7.

Scholl, L., P. Seth, M. Kariisa, N. Wilson and G. Baldwin (2019) 'Drug and Opioidinvolved Overdose Deaths-United States, 2013-2017', Morbidity and Mortality Weekly Report, 67(51-52), pp.1419-1427, DOI: 10.15585/mmwr.mm675152e1.

Smith, G. (2019) 'Congress Should Condemn Trump's Shoddy Drug Strategy', The Hill, 18 March, https://thehill.com/opinion/healthcare/433231-congress-should-condemntrumps-shoddy-drug-strategy (accessed on 27 April 2020).

Strang, J., T. Groshkova and A. Uchtenhagen (2015) 'Heroin on Trial: Systematic Review and Meta-analysis of Randomised Trials of Diamorphine-Prescribing as Treatment for Refractory Heroin Addiction', British Journal of Psychiatry 207(1), pp. 5-14, DOI: 10.1192/bjp.bp.114.149195.

UNAIDS (Joint UN Programme on HIV/AIDS) (2019) Health, Rights and Drugs-Harm Reduction, Decriminalization and Zero Discrimination for People Who Use Drugs (Geneva: United Nations), https://www.unaids.org/en/resources/documents/2019/ JC2954_unaids_drugs_report_2019 (accessed on 27 November 2019).

Vancouver City Council (2019) Administrative Report:Mayor's Overdose Emergency Task Force. Vancouver, https://vancouver.ca/people-programs/safe-supply-statement. aspx (accessed on 25 November 2019).

Williamson, M. (2005) 'The History, Operations and Achievements of the Royal Project', UNODC Eastern Horizons (Summer/Autumn), pp. 10-11, https://www.unodc. org/documents/southeastasiaandpacific/Publications/eastern_horizons/EH21.pdf (accessed on 27 April 2020). 
Wilson, D.P., B. Donald, A.J. Shattock, D. Wilson and N. Fraser-Hurt (2015) 'The CostEffectiveness of Harm Reduction', International Journal of Drug Policy, 26(Supp. 1), pp. S5-S11, DOI: 10.1016/j.drugpo.2014.11.007.

WHO (World Health Organization) (2011) Ensuring Balance in National Policies on Controlled Substances: Guidance for Availability and Accessibility of Controlled Medicines (Geneva: United Nations), https://apps.who.int/iris/handle/10665/44519 (accessed on 25 November 2019).

Woolf, S.H. and H. Schoomaker (2019) 'Life Expectancy and Mortality Rates in the United States, 1959-2017', Journal of the American Medical Association 322(20), pp. 19962016, DOI: 10.1001/jama.2019.16932. 